\title{
SOME ASPECTS OF COMMUNITY PSYCHIATRY
}

\author{
BY
}

\author{
JOHANNES NIELSEN, WILLIAM WILSNACK, AND ERIK STRÖMGREN \\ Institute of Psychiatry, Airhus State Hospital, Risskov, Denmark
}

The purpose of this paper is to describe some aspects of community psychiatry in relation to a community psychiatric project in a geographically delimited area in Denmark.

Leighton and Longaker (1957) described some aspects of the psychiatric clinic as a community innovation from the experience gained in the Bristol psychiatric clinic in Stirling County where approximately 2 per cent. of the 20,000 inhabitants were seen as patients in the clinic or in their homes during the first 5 years of the project. The experience gained in the Stirling County study has been further discussed in later publications (Leighton, 1959; Hughes, Tremblay, Rapaport, and Leighton, 1960). Carse, Panton, and Watt (1958) described community psychiatry in the Worthing area with a population of 160,000 , where all patients with mental illness referred by general practitioners are seen by psychiatrists before the decision about admission to a mental hospital is made. During the first $\mathbf{1 0}$ months of this service, 1,192 patients were referred and 1,000 domiciliary visits were paid to 432 of them. The admission rate fell by $\mathbf{4 0}$ per cent. during this period, because of the many instances in which the psychiatrist concluded that admission to a mental hospital was not necessary.

More than half the time of the consultants at the Mapperly hospital is spent in extramural activities in the Nottingham community psychiatric services (Macmillan, 1956, 1958a, b, 1963). Macmillan regards domiciliary visits to psychiatric patients as extremely important and in many respects superior to the use of out-patient clinics. He mentions that a community mental health scheme makes it possible to see almost all patients referred to psychiatric institutions at home and to decide upon the appropriate in-patient unit before admission. He stresses the importance of liaison with the general practitioners, saying that in the future we shall talk less about the number of beds in the hospital and more about the size of the community it serves. In planning for the future, according to Macmillan, a population of 250,000-300,000 would seem to be the maximum for a mental health service. Querido (1954) and Millar and Henderson (1956) described the community mental health service in Amsterdam where extensive use of domiciliary service is made. Sainsbury and Grad (1962) and Grad and Sainsbury (1963) have made comparative studies of the burden on the family and the results of treatment in the hospital-centred conservative psychiatric treatment service in Salisbury and the community psychiatric service in Chichester. Introduction of the community service in Chichester caused an average fall in admission of 43 per cent. (55 per cent. from within 10 miles of the hospital and 14 per cent. from more distant areas). The overall relief for the patients' families was greater in the hospital-centred service, but families whose burden was heavy were equally relieved in both. Although the admission rate was twice as high in the hospital-centred service, relief was not more closely related to admission in one service than in the other. Analysis of the clinical features of the patients and of the social characteristics of their families indicated that relief to families in a community-care service can approach relief in a hospital-centred service. May, Sheldon, and MacKeith (1962), in a report of the future of district psychiatry, describe the attempt of the Croydon psychiatric service to change hospital-oriented psychiatry to a comprehensive system of district psychiatry. They mention that general practitioners play a crucial part in the district psychiatric service and stress that home visits with support and advice to family, relatives, and others in the immediate environment are of great importance in treatment. May and Moore (1963) describe the value of the mental nurse in community psychiatry, especially in the treatment of geriatric patients. Domiciliary visits are used in a psychiatric clinic established by the Oslo Helseråd 
(Hirsch, 1963). A psychiatric home treatment service was initiated in 1957 at the Boston State Hospital for a population of 80,000 people (Friedman, Rolfe, and Perry, 1960). Coleman and Zwerling (1959) described an emergency psychiatric clinic with home visiting from the Bronx Municipal Hospital. Leyberg (1959) described a district psychiatric service for a population of about 180,000 . Of 188 patients visited at home for diagnosis, 20 per cent. remained at home under care of the general practitioner, 36 per cent. were treated in the out-patients clinic, and 44 per cent. were admitted for either in-patient or dayhospital treatment. He stressed the importance of screening as many patients by home visits as possible before the place and type of psychiatric treatment is decided upon. Lyle (1959) emphasized the need for a close liaison between the different psychiatric services in a community, and between these services, the public health agencies, and the social welfare departments. Bellak (1960) described a psychiatric ward with 120 beds, twelve full-time psychiatrists, fifteen residents, ten psychologists, and six social workers as a focus of community psychiatry for a population of 2 million with separate psychiatric seminars for general practitioners, chaplains, guidance teachers, and lawyers, and with an open ambulatory clinic; he also described plans for a psychiatric consultation centre open to all physicians in the community. Lewis (1962) stated, as basic principles in modern community care, that patients should be kept in their home communities and treated there whenever possible, and that patients should be seen early in the course of their illness, making it possible to avoid hospitalization in many instances. He stressed the importance of emergency treatment and after-care service in each community. Cameron (1961) described a county psychiatric emergency service, saying that there was no substitute for a visit in the patient's home. "In a few minutes an experienced observer can gain more pertinent information about the patient and his environment by a home visit than can be gained during hours of probing in an office, using miles of recording tape, and hours of typing time." Freyhan and Mayo (1963) found that a clinic with access to all psychiatric facilities including in-patient service, dayhospital service, and ambulatory service with possibilities for home visiting is the ideal setting as a centre of community psychiatric service. Buckle (1962) emphasized the importance of a screening procedure, so that all patients referred to mental hospitals could be seen in their homes before admission by a psychiatrist available for emergency calls. The advantage of engaging hospital psychiatrists in emergency work and domiciliary visiting is that admissions to mental hospitals can be deliberately planned for specific purposes with a time limit. Many chronically-ill psychiatric patients, particularly the elderly and those with concurrent physical disorders, can be brought into hospital for a few weeks for special examinations and somatic treatment, thus providing some relief for the family and giving an opportunity for active social case-work so that better care may be provided for the patient on his return home.

It runs as a red thread through all these reports that community psychiatry is important for diagnostic and therapeutic purposes, and for screening patients with mental illness before any decision is made regarding treatment. It is also important in rehabilitation and prevention, and is an effective tool in breaking down the prejudice, apprehension, and fear of the public concerning mental illness and mental hospitals.

\section{The Samsø Project}

The Samsø Project was started in 1957 as part of a psychiatric demographic research project comprising Århus county and the island of Samsø. One purpose was to investigate the use that a geographically delimited population will make of a psychiatric service when given easy and free access to it through the local general practitioners and the physicians at the general hospital serving the area. Data were collected of the incidence of psychiatric disorders in this population and of the consequent need for psychiatric treatment.

A survey of the first 5-year period in the psychiatric clinic in Samsø was made by Nielsen, Juel-Nielsen, and Strömgren (1962).

\section{The IsLAND OF SAmsø}

Location.-Samsø lies in the Kattegat between Jutland and Zealand (Fig. 1, opposite), 2 hours by ferry from Århus in Jutland and Kalundborg in Zealand. The island is not very isolated because of daily ferry connexions with Jutland, and the summer tourist invasion. It belongs to the county of Holbak in Zealand and until recently it was divided in five parishes, but these are now united in one parish administered from Tranebjerg, which is the largest village in the island with approximately 800 inhabitants.

Land Utilization.-Samsø consists of 28,151 acres, of which 22,396 are farming land and 1,961 forests and plantations. More than half of the farms have less than 50 acres, most of the bigger ones 75 to 100 acres, and only a very few more than 150 acres; 


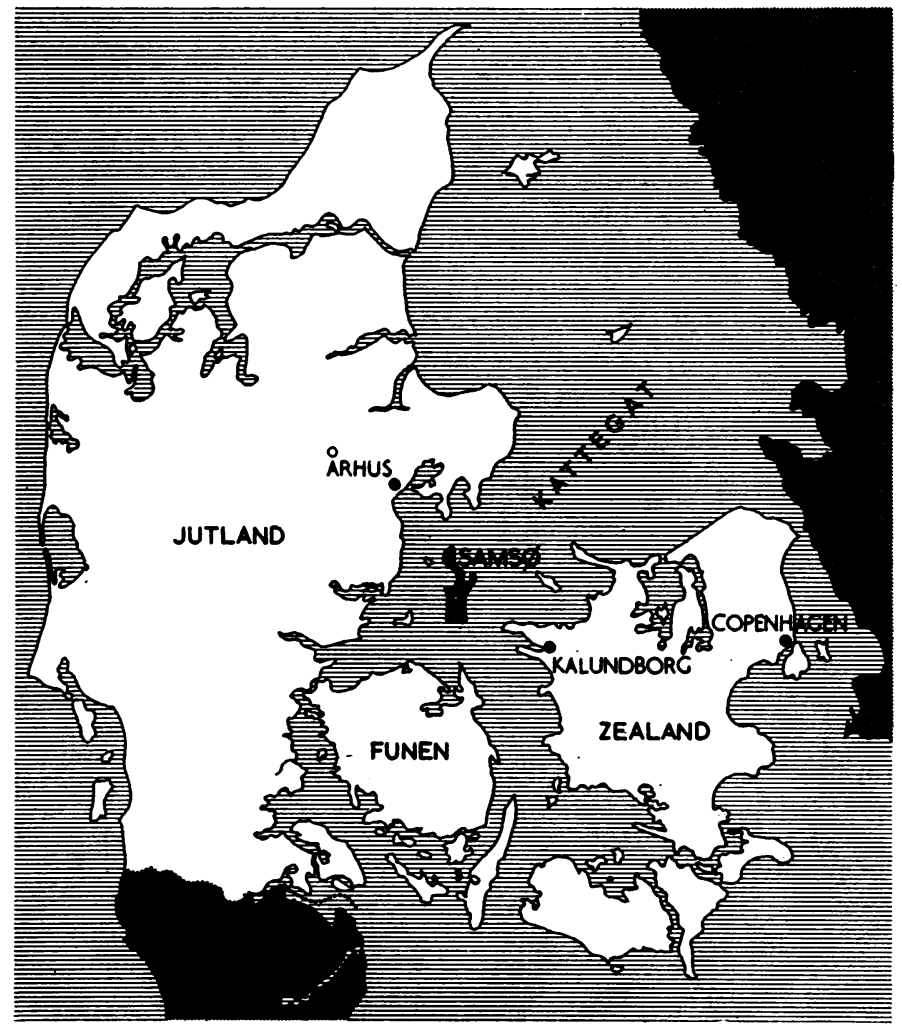

Fig. 1.-Denmark, showing position of Samse.

there is one very big estate of 5,930 acres of which 1,960 are forests and plantations.

Population.-The population in Samsø increased from 4,049 in 1801 to a peak of 7,500 in 1911, and by 1961 it had decreased to 6,189 . The sex ratio and age distribution is shown in Fig. 2. Other rural districts in Denmark have also had a considerable decrease in population because the younger people have moved to the cities, but this movement has been more marked in Samsø during the last decade, so that the percentage in the 20 to 24-year age group is approximately half and in the 25 to 29-year age group three-quarters of that in other rural districts in Denmark. The percentages in the other groups are the same as elsewhere. The population is relatively stable, only 33 per cent. being born outside the island, and the consanguinity rate of 0.7 per cent. for firstcousin marriages corresponds with that in other rural districts in Denmark.

Economy.-The population is relatively wealthy, farming being the main source of income. Of the males above 15 years of age, 54 per cent. are occupied in farming, 19 per cent. in commerce, trade, and

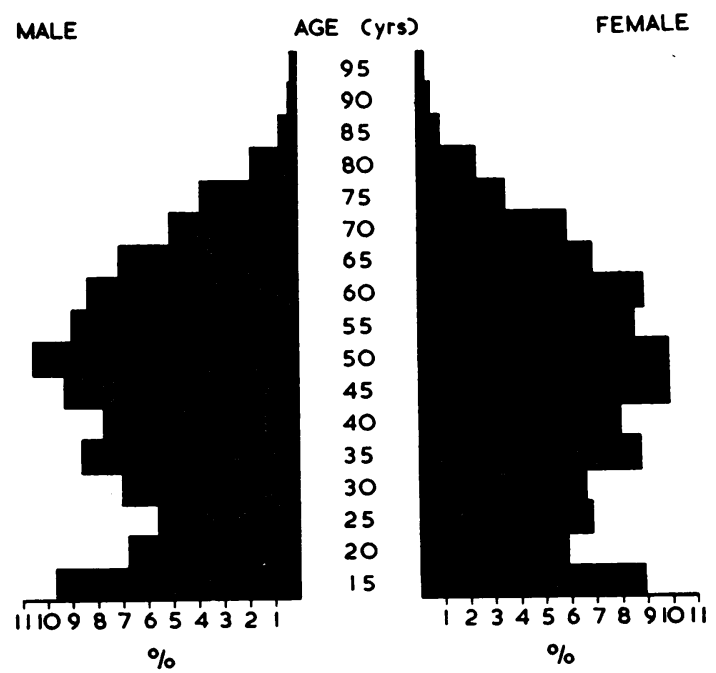

Fig. 2.-Population of Samsø aged $15+$ on January 1, 1959, by sex and age group.

industry, 3 per cent. in fishing, and only 2 per cent. in unskilled labour. Very few of the women above 15 years of age work outside their homes. 


\section{The Psychiatric Clinic}

This is for out-patients only and is located in the building where the general practitioners have their consulting rooms. There is a room at the hospital for ECT treatment of both in-patients and out-patients. Only the two general practitioners and the hospital physicians refer patients to the psychiatric clinic, which is free.

During the first 5 years in which the clinic has existed, a psychiatrist has visited the island at least once a week, assisted when necessary by psychologists. It has been run by young psychiatrists under senior supervision who have spent approximately 2 days a week in the island, and have undertaken other research projects for the rest of their time. So far no social workers have been connected with the clinic.

During these 5 years 600 patients have been referred. Those under 15 years, constituting 8 per cent. of the population, were described by Lange (1960). Patients of 15 years and above constituted 9.7 per cent. of the population (Nielsen and others, 1962). Other studies of the Samsø Project have been made by Lange, Mogensen, and Fenger (1960), Mogensen, Lange, and Fenger (1960), Sørensen and Strömgren (1961), B. F. Sørensen (1961), A. Sørensen (1962), and Nielsen (1962a, b, c, 1963, 1964, 1965).

\section{DiAgnOSES}

The distribution of the 472 patients referred during the 5-year period is seen in Table I, with the rate per 1,000 population aged $15+$.
Diagnosis was made in accordance with the recommendations of the Danish Psychiatric Society.

The term schizophrenia is used in a narrower sense, and the term manic-depressive psychosis in a wider sense in Denmark than in most other countries (Arentsen and Strömgren, 1959). Most of the latter are cases that do not show the typical oscillations between mania and depression; one fourth of them being mild cases of depression as described by B. F. Sørensen (1961)-manifesting reduced zest for life, feelings of insufficiency, and self-reproach, with such somatic complaints as tiredness and hypochondriawhich respond well to anti-depressive drug therapy.

Psychogenic depression includes psychoses which arise in immediate connexion with mental stress, the symptomatology and course being in most cases influenced by mental trauma (Faergeman, 1963). In Anglo-Saxon psychiatry, a number of these cases are usually described as schizophrenias or neuroses.

Paranoid psychosis includes psychoses dominated by delusions that are not accessory psychiatric disturbances in schizophrenia, manic-depressive psychosis, mental deficiency, or dementia.

Senile and arteriosclerotic psychoses follow the same diagnosis as in Anglo-Saxon psychiatry.

Other organic psychoses include psychiatric 8 symptoms in connexion with cerebrovascular attacks or their sequelae, previous encephalitis, and delirium or severe depression in relation to somatic disease.

Epilepsy, neuroses, character-disorder, and alcoholism are diagnosed in accordance with Anglo-Saxon psychiatric classifications.

TABLE I

PATIENTS AGED 15+ REFERRED FOR THE FIRST TIME TO THE PSYCHIATRIC CLINIC IN SAMSØ, 1957-62, BY SEX, DIAGNOSIS, AND RATE PER 1,000 OF POPULATION AGED 15 + ON JANUARY 1, 1959

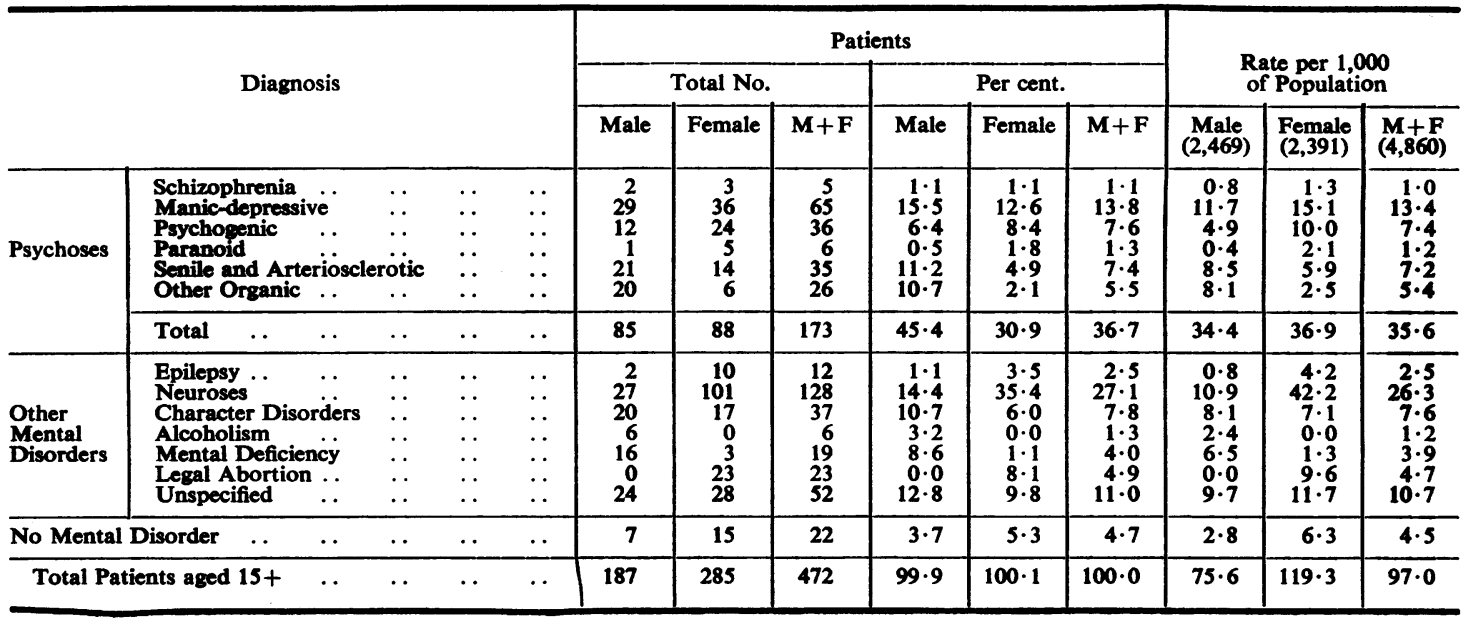


Mental deficiency also includes intellectual inferiority.

Legal abortion describes patients referred for investigation of possible abortus provocatus on account of mental disease.

Unspecified mental disorder comprises patients with neurological disease and psychiatric symptoms, and patients with hypochondria, fluctuating anxiety, or nervous symptoms, without real neurotic or psychotic traits.

Of the patients with no mental disorder, 80 per cent. are neurological cases.

Attitude of the Population towards Mental Illness AND the Psychiatric Service

Before 1957, when the psychiatric clinic in Samsø was started, no ambulatory psychiatric treatment had been given within the community. Patients with mental illness always had to be admitted to the Århus State Hospital, and the average annual number of patients from Samsø in 10 years before 1956 was 6.7 , whereas an average of 94.4 patients per year was referred to the new psychiatric service. In the 5 years 1957-61, 3,228 consultations were given, 1,451 of which were home visits. Thus many more families had personal contact with a psychiatrist, when the psychiatric service moved out from the hospital into the community. This was a very valuable means of modifying fearful and rejective attitudes towards mental illness and psychiatric treatment.

It is most important that all the aims of the clinic and the research projects are explained to and discussed with the local physicians, teachers, priests, and nurses, whose co-operation is of the greatest value.

In 1957 some patients were afraid to have the psychiatrist's car parked outside the house, as everybody in the village would know that somebody in the family was mentally ill. This attitude towards home visits has now changed considerably and most patients prefer to be treated at home. This prejudice only persists in villages where very few persons have had psychiatric treatment, or where the local gossips are for some reason hostile to the psychiatric service or to patients with mental illness. In one such case there were rumours that the existence of serious mental disorder requiring home visits might cause a rise in the health insurance rate in the island. It was also found that those with unfavourable attitudes towards patients with mental illness were themselves known as being "nervous", a not unusual reason for a negative attitude.

In another case a patient who objected to home visits by the psychiatrist, for fear of what the neigh- bours would say, changed her attitude and asked the psychiatrist to call, because she found that some of her neighbours had been treated at home and had a favourable attitude towards the psychiatric service. These were the only two cases who refused psychiatric home visits out of approximately 200 patients seen by one of us (J.N.), and in none of approximately 600 home visits did he meet aggression or feel unwelcome. There was sometimes a slight sense of coolness, insecurity, or indifference at the first visit, but this always disappeared during the following visits.

Of the 472 patients referred during the first 5 years, 245 had a clear feeling of being in need of psychiatric treatment.

\section{Co-ordination of Health Services in the Community}

In order to make a community psychiatric service efficient, it is extremely important to integrate it with the welfare services already existing, and contact should also be established with other societies and institutions.

In Samsø the existing health service, apart from the psychiatric service, comprises two general practitioners, a general hospital with 36 beds staffed by two full-time physicians, a nursing home with fourteen beds, two geriatric homes with room for thirty persons, three district nurses, one child-health nurse, and two midwives. There is access to a state mental hospital in Århus, a central hospital with special wards for internal medicine and surgery in Kalundborg, a neurological and neurosurgical hospital in Århus, and cardiological, ear, nose, throat, and eye services in Århus or Copenhagen (Fig. 1). There is also access to the mother's help service in Holbæk and a rehabilitation centre in Slagelse, both cities in Zealand.

There are five protestant priests serving the island churches. There is a Lions Club and a Rotary Club, but very few of the islanders are members of the country-wide Mental Hygiene Society or the Welfare Society for the Mentally-retarded and Mentally-ill.

The psychiatric service was started in 1957 in close co-operation with the general practitioners and the physicians in the general hospital, without which it would not be able to function (Carse and others, 1958; Macmillan, 1963).

Medical care is so organized in Denmark that it would be difficult to let patients come directly to the psychiatric clinic without referral by a physician belonging to the organization of the general practitioners or by a medical specialist. In some areas one might gain a better picture of the need for psychiatric 
treatment if patients could come direct to the clinic, but in Samsø there is such close personal contact between the physicians and the psychiatrists that direct access would make little difference.

Referral Rate.-That the referral rate depends on the referring physicians was shown by Rawnsley and Loudon (1962), and this is supported by our findings in Samsø.

Table II shows patients referred by the general practitioners (A, B, C, and D) and the hospital physicians (E). A, B, and C covered the southern part of the island (comprising 4,296 persons), and $D$ covered the northern part of the island (comprising 691 persons).

$A$ and $B$ worked together until towards the end of 1959, when A sold his share of the partnership to C. There is little difference between the number of patients referred by $\mathrm{A}$ and $\mathrm{B}$, but there is a considerable difference between $B$ and $C$ during $C$ 's first 2 years. This was partly because $C$ did not have so many patients as $B$ until he became familiar with the population, but mainly because, until 1961 , when the number referred by $C$ rose above the number referred by $B$, the psychiatrists had made too little effort to bring $\mathrm{C}$ into the scheme.

$D$ referred approximately the same number of patients every year except 1960 . He referred 18.9 per cent. of the patients although the population he covered comprised only 13.9 per cent. of the total; this difference is thought to be due to his special eagerness to refer all patients with mental illness to the psychiatric service.

There is no great difference in the diagnostic distribution of the patients referred by the four general practitioners. Our experience agrees with the findings of Rawnsley and Loudon (1962) that general practitioners are influenced to a varying degree by social and attitudinal factors in deciding on referral to a psychiatric service. These differences become less when there is good co-operation between the psychiatrists and the general practitioners.
This need for co-operation is emphasized by the rise in the numbers referred from the general hospital in Samsø from an average of four per year in 1957 to 1960 to 35 in 1961, when weekly visits were paid to the hospital by one psychiatrist, who treated patients referred, discussed problems concerning patients with mental illness with both physicians in the hospital, and accompanied them on ward rounds from time to time.

Procedure.-When a patient is referred, the referring physician is contacted by the psychiatrist, and the patient and his family are discussed. This information and the general practitioners' case records together give a very good picture of the patient.

The general practitioner is at all times kept informed about the treatment and its results; it is especially important for him to be advised what to do when the psychiatric treatment is finished.

It is also important to make ward rounds with the physicians at the hospital.

Close co-operation between the psychiatrists, the district nurses, and the child-health nurses is desirable but has not yet been organized in Samsø; similarly co-operation with the staff of the geriatric and nursing homes paying visits once or twice a month would be of great value. It was found by one of us (J.N.) from visiting the geriatric homes as well as the general hospital that the most valuable result was the creation of an understanding, helpful, tolerant, and optimistic attitude towards patients with mental illness. This is assisted by prompt and efficient treatment of mental illness with admission of such patients to a psychiatric hospital without delay. With the community psychiatric service screening all patients and taking care of approximately 80-90 per cent. of the referred patients, there should be no waiting list for admission, provided that the number of psychiatric beds is kept at about $2 \cdot 5$ to 3 per 1,000 and not reduced to $1 \cdot 8$ to 2 per 1,000 , as was suggested in England (Tooth and Brooke, 1961).

TABLE II

DISTRIBUTION OF PATIENTS AGED 15 + BY YEAR, AND REFERRING PHYSICIAN, 1957-61

\begin{tabular}{|c|c|c|c|c|c|c|c|}
\hline \multirow{3}{*}{\multicolumn{2}{|c|}{ Year }} & \multicolumn{5}{|c|}{ Referral } & \multirow{3}{*}{ Total Patients } \\
\hline & & \multicolumn{4}{|c|}{ By the General Practitioners } & \multirow{2}{*}{$\begin{array}{c}\text { By Hospital Physicians } \\
\text { E }\end{array}$} & \\
\hline & & $\mathbf{A}$ & B & $\mathbf{C}$ & $\mathbf{D}$ & & \\
\hline $\begin{array}{l}1957 \\
1958 \\
1959 \\
1960 \\
1961\end{array}$ & & $\begin{array}{l}43 \\
42 \\
34 \\
=\end{array}$ & $\begin{array}{l}34 \\
38 \\
36 \\
33 \\
20\end{array}$ & $\begin{array}{r}- \\
9 \\
18 \\
27\end{array}$ & $\begin{array}{l}20 \\
22 \\
15 \\
11 \\
19\end{array}$ & $\begin{array}{r}3 \\
0 \\
5 \\
8 \\
35 \\
\end{array}$ & $\begin{array}{r}100 \\
102 \\
99 \\
70 \\
101\end{array}$ \\
\hline Total $\ldots$ & .. & 119 & 161 & 54 & 87 & 51 & 472 \\
\hline
\end{tabular}


Treatment of Chronic Patients, Home Visits, AND Follow-UP

One of the great advantages of community psychiatry is the possibility of treating chronic patients within the community and the ease with which patients discharged from the local mental hospital can be followed up.

Out of 472 patients referred during the first 5-year period there were eighteen who had previously been admitted to Arrhus State Hospital several times but who could now be treated within the community and could live in their own homes during long periods. Sixteen of these patients had psychoses, eleven were manic-depressive, two were schizophrenics, one had a paranoid psychosis, and two had senile psychoses. At the end of 196126 patients were under treatment; seven had been followed for 3 to 5 years, six for 2 to 3 years, two for 1 to 2 years, and eleven for from 1 to 11 months. Thirteen of these 26 patients were manicdepressives, three had psychogenic psychoses, four schizophrenia, and six neuroses.

Of the 53 patients who were admitted to a psychiatric hospital during 1957-61, only six were still in the hospital at the end of the period, all with psychoses or severe dementia. The rate of patients hospitalized was $1 \cdot 4 / 1,000$ and that of patients under treatment in the community was $5 \cdot 3 / 1,000$.

That only six patients with neuroses were under treatment shows that there is no need to fear that the load of neurotic patients will be overwhelming when access to the psychiatric service is so easy. A visit once a month or every 2 weeks to patients with chronic mental illness or with recurrent manicdepressive psychoses is of great importance in preventing exacerbation of the disease or in stopping a depression immediately by anti-depressive medication, by raising the dosage, or by giving electroconvulsive therapy. The number of patients referred more than once to the psychiatric service was rising from 3,5 , and 7 in 1957, 1958, and 1959 to 23 and 37 in 1960 and 1961.

In community psychiatry, follow-up is much fuller than is revealed by the figures in the official reports. By visiting patients all over the island, the psychiatrists often meet previous patients or their relatives and naturally discuss the patient's present condition. Previous patients may also be visited when neighbours are visited, or may be seen at the local hospital if they attend for somatic disorder.

When the treatment is finished patients are always told that they are welcome to return to the clinic without any official referral; this easy means of contact with the psychiatric service is extremely important for patients with a latent fear of relapse as well as for their families.
Many "chronic" patients now living in mental hospitals could easily live with their families, in hostels, in day or night hospitals, or in nursing homes, if a community psychiatric service was available and the psychiatrist could pay them regular visits. The value of home visits has previously been described by Nielsen (1963).

Of the 3,228 consultations given during the 5-year period, 45 per cent. were home visits paid to 241 of the 472 patients. 68 per cent. of the psychotic and 46 per cent. of the neurotic patients were visited in their homes at least once, many of them, especially the psychotic patients several times. For the five psychiatrists working in the clinic for from 9 to 40 months, the percentage of home visits varied from 20 to 60 , being highest for those with the greatest proportion of psychotic patients.

One home visit is of diagnostic importance in nearly all patients with mental illness, and is of therapeutic importance in all elderly patients and all psychotic patients except paranoids. Therapeutic home visits should never be paid to alcoholics and patients with character disorders, but may be useful for neurotic patients especially in conjunction with supportive and dynamic family therapy.

Home visiting also helps to establish a positive attitude in the population towards mental illness, breaking down prejudice and hostility towards mental hospitals. Such measures as changing the names of mental hospitals, unlocking doors, and improving conditions throughout these institutions have not been sufficient to change the deep-seated fear of mental hospitals and mental illness.

Home visiting is the ideal means of studying the interrelationship of mental health in the members of a family and so assists the treatment of any member with mental illness.

\section{Treatment of Elderly Mental Patients in the COMMUNITY}

The prevalence of mental disorder in elderly people in Samsø was found to be 7 per 1,000 for psychoses, of which 45 per cent. were affective psychoses (Nielsen, 1962b). The advantage of treating them in the community has previously been described by Nielsen (1962a, 1965), but it may be mentioned here that the referral rate of persons aged $65+$ was $15 \cdot 5$ per 1,000 per year, but only 1.5 per $1,000 \mathrm{had}$ to be admitted to the psychiatric hospital.

Of the 363 consultations given to the 73 patients aged $65+, 64$ per cent. were home visits, and 22 per cent. were consultations in the general hospital. Only 13 per cent. of these consultations took place in the clinic compared with 53 per cent. of those to patients aged 15 to 64 years. In community psychiatry a home 
visit can be paid as soon as a patient is referred, and this can prevent nearly all psychoses becoming as severe as those often seen in elderly patients admitted to mental hospitals after months or years of illness. The creation of an understanding, optimistic, tolerant, and helpful attitude in the patient's family is most important, and this can only be achieved by home visiting.

A home visit once or twice a month is valuable as a supportive or preventive measure against desolation and loneliness, and as a therapeutic measure in affective or partly affective organic depressions in elderly persons.

Community psychiatry permits the necessary longterm follow-up. Elderly persons with affective psychoses often deteriorate as far as behaviour is concerned when moved to mental hospitals, and are much better treated in their usual surroundings by only one or two physicians with whom they are familiar.

To reach the stage where the 6 to 7 per cent. of elderly psychotics are examined by psychiatrists, and at least the 3 to 4 per cent. suffering from affective psychoses are treated, a well-integrated community psychiatric service is required.

The Importance of having a Psychiatric Service along With a Psychiatric Demographic

Research Project

Without the psychiatric service it would have been difficult if not impossible to run the research project. Difficulties of co-operation between the psychiatrists and the physicians in the island and disagreements among the psychiatric team were minimized by the demands for treatment of the patients referred. The fascinating work in this type of psychiatric clinic kept everyone occupied, while the research project was organized on a sound basis.

The investigation of psychiatric problems among patients in the general hospital brought about better co-operation with the hospital physicians and the integration of the psychiatric service with the general hospital service. This investigation was made during 6 months when 187 patients were admitted to the hospital, some of them several times (Table III). 22 per cent. of these patients were referred to the psychiatric service by the hospital physicians compared with only about 1 per cent. during the first 4 years of the project. Of the 187 patients, 36 per cent. were found to have some kind of mental disorder. 25 per cent. of the surgical patients and 51 per cent. of the medical patients had some kind of mental illness. Such investigations would have been practically impossible if no treatment could have been offered to those in need, and, on the other hand, the investigation itself created a better understanding of patients with mental illness among the nurses and physicians. This illustrates the important interaction between research and clinical work. Our psychiatric epidemiological investigation would have been difficult and frustrating if we could not have given treatment to those found to be in need.

Intensive studies of 59 unselected school beginners and their parents by a child psychologist and psychiatric social worker in 1959 and 1962 (Haslund, 1962) had 100 per cent. voluntary participation, as did a similar investigation of 122 unselected 10-yearold children by a psychiatrist and a social worker in 1959 (Lange, 1960). This 100 per cent. co-operation in such extensive investigations requiring severalc hours of interviewing may well have been due to the parents' acceptance of the psychiatric service and to their recognition of its value for their children as well as for themselves.

\section{SUMMARY}

A community psychiatric service together with a psychiatric demographic research project on an island with a total population of 6,189 are described.

During the first 5 years 472 patients aged 15 + were referred for the first time to the psychiatric clinic ( $9 \cdot 7$ per cent. of a population of 4,860$)$, an average referral rate of $19 \cdot 4$ per 1,000 per year.

The attitude of the population towards this intensive psychiatric service and psychiatric research

TABLE III

DISTRIBUTION OF PATIENTS AGED 15+ ADMITTED TO GENERAL HOSPITAL IN 6-MONTH PERIOD, BY AGE, SEX, MENTAL ILLNESS, AND REFERRAL TO PSYCHIATRIC SERVICE

\begin{tabular}{|c|c|c|c|c|c|c|c|c|c|c|c|c|c|}
\hline Sex & . & $\cdots$ & $\cdots$ & \multicolumn{4}{|c|}{ Male } & \multicolumn{4}{|c|}{ Female } & \multirow{2}{*}{\multicolumn{2}{|c|}{$\frac{\mathbf{M}+\mathbf{F}}{\text { All Ages }}$}} \\
\hline \multirow[t]{2}{*}{ Age (yrs) } & \multirow[t]{2}{*}{. } & \multirow[t]{2}{*}{$\cdots$} & \multirow[t]{2}{*}{$\cdots$} & \multicolumn{2}{|c|}{$15-64$} & \multicolumn{2}{|c|}{$65+$} & \multicolumn{2}{|c|}{$15-64$} & \multicolumn{2}{|c|}{$65+$} & & \\
\hline & & & & No. & Per cent. & No. & Per cent. & No. & Per cent. & No. & Per cent. & No. & Per cent. \\
\hline \multicolumn{3}{|c|}{$\begin{array}{c}\text { Total Patients admitted to } \\
\text { General Hospital }\end{array}$} & . & 44 & - & 30 & - & 72 & - & 41 & - & 187 & - \\
\hline \multicolumn{4}{|c|}{$\begin{array}{l}\text { Mental Disorder } \\
\text { Referral to Psychiatric Service }\end{array}$} & $\begin{array}{l}15 \\
10\end{array}$ & $\begin{array}{l}34 \\
23\end{array}$ & $\begin{array}{r}16 \\
6\end{array}$ & $\begin{array}{l}53 \\
20\end{array}$ & $\begin{array}{l}19 \\
16\end{array}$ & $\begin{array}{l}26 \\
22\end{array}$ & $\begin{array}{r}17 \\
9\end{array}$ & $\begin{array}{l}41 \\
22\end{array}$ & $\begin{array}{l}67 \\
41\end{array}$ & $\begin{array}{l}36 \\
22\end{array}$ \\
\hline
\end{tabular}


project changed from indifference to a positive and helpful attitude.

The importance of the co-ordination of the psychiatric service with the various health and welfare services is discussed. Co-operation between the psychiatrists and the general practitioners is of the greatest importance, as well as that with hospital physicians, health visitors, teachers, and clergymen.

Co-operation with the staff of the geriatric homes and the nursing homes, with visits paid to these institutions once or twice a month, is of importance in prevention and treatment of psychiatric disorders.

In a community psychiatric service, home visits, early intervention, family treatment, and the longterm follow-up of chronic patients offer important advantages over a hospital-bound service. The special importance of treating elderly people with mental illness in the community is stressed.

In the Samsø Project it has been found of the greatest value to be able to offer extensive psychiatric treatment to the population in an area where intensive psychiatric research is being carried out.

\section{REFERENCES}

Arentsen, K., and Strömgren, E. (1959). "Patients in Danish Psychiatric Hospitals". Universitetsforlaget, Århus, and Munksgaard, Copenhagen.

Bellak, L. (1960). J. Amer. med. Ass., 174, 2214.

Buckle, D. F. (1962). "Some Developments of Psychiatric Practice in Europe". WHO Regional Office for Europe. Cameron, W. R. (1961). Publ. Hlth Rep. (Wash.), 76, 357.

Carse, J., Panton, N. E., and Watt, A. (1958). Lancet, 1, 39.

Coleman, M. D., and Zwerling, I. (1959). Amer. J. Psychiat., 115, 980.

Faergeman, P. M. (1963). "Psychogenic Psychoses". Butterworth, London.

Freyhan, F. A., and Mayo, J. A. (1963). Amer.J. Psychiat., 120, 222.

Friedman, T. T., Rolfe, P., and Perry, S. E. (1960). Ibid., 116, 807.

Grad, J., and Sainsbury, P. (1963). Lancet, 1, 544.

Haslund, L. (1962). "Planning and Beginning of a Longitudinal Study of 59 Unselected School Beginners".'Paper read at the V International Congress of Child Psychiatry, Scheveningen, September 24-30, 1962.

Hirsch, J. (1963). Personal communication.

Hughes, C. C., Tremblay, M., Rapaport, R. N., and Leighton, A. H. (1960). "People of Cove and Woodlot". Basic Books, New York.

Lange, B. (1960). Ugeskr. Laeg., 122, 1335.

, Mogensen, A., and Fenger, G. (1960). Nord. psykiat. $T ., 4,286$.

Leighton, A. H. (1959). "My Name is Legion. The Stirling County Study", vol. 1. Basic Books, New York.

and Longaker, A. (1957). In "Explorations in Social Psychiatry", ed. H. H. Leighton, J. A. Clausen, and R. N. Wilson, pp. 365-85. Basic Books, New York.

Lewis, F. A. Jr. (1962). J. Amer. med. Ass., 182, 323.

Leyberg, J. T. (1959). Lancet, 2, 282.

Lyle, J. (1959). "Mental Health in the Community and Some Aspects of Prevention". WHO Conference on Mental Hygiene Practice, Helsinki.

Macmillan, D. (1956). Lancet, 2, 1094.

- (1958a). J. soc. Psychiat., 4, 5. (1958b). Lancet, 2, 201.

- - (1961). In "Proceedings of the Third World Congress of Psychiatry", Montreal, vol. 1, p. 209 (publ. 1963).

- (1963). Lancet, 1, 567.

May, A. R., and Moore, S. (1963). Ibid., 1, 213.

Sheldon, A. P., and MacKeith, S. A. (1962). Ibid., $2,1319$.

Millar, W. M., and Henderson, J. G. (1956). Int. J. soc. Psychiat., 2, 141.

Mogensen, A., Lange, B., and Fenger, G. (1960). Nord. Psykol., 12, 302.

Nielsen, J. (1962a). Ugeskr. Lreg., 124, 1652.

- (1962b). Acta psychiat. scand., 38, 307.

- (1962c). Ugeskr. Laeg., 124, 1108.

- (1963). Comprehens. Psychiat., 4, 442.

(1964). Brit. J. Psychiat., 110, 683.

(1965). Gerontol. clin. (Basel), 7, 148.

, Juel-Nielsen, N., and Strömgren, E. (1962). Ugeskr. Laeg., 124, 1103.

Querido, A. (1954). Wld ment. Hlth, 6, 203.

Rawnsley, K., and Loudon, J. B. (1962). Brit. J. prev. soc. Med., 16, 174.

Sainsbury, P. and Grad, J. (1962). "The Epidemiology of Mental Illness". Oxford University Press, Oxford.

Sørensen, A. (1962). Paper read at the XIII Nordiske Psykiaterkongres, Helsinki, June 13-16, 1962.

- and Strömgren, E. (1961). Acta psychiat. scand., 37, suppl. 162 , pp. $62-8$.

Sørensen, B. F. (1961). Ibid., 37, suppl. 162, pp. 105-11.

Tooth, G. C., and Brooke, E. M. (1961). Lancet, 1, 710. 